\title{
Simulasi CFD Pengaruh Penggunaan Deflektor Pelat Lengkung terhadap Performa Turbin Air Savonius Sumbu Vertikal Dua Sudu
}

\author{
Fakhrul Widyantama*, Doddy Suanggana dan Gad Gunawan \\ Program Studi Teknik Mesin, Jurusan Teknologi Industri dan Proses, Institut Teknologi Kalimantan, \\ Jl. Soekarno-Hatta Km. 15, Karang Joang, Balikpapan, Kalimantan Timur, 76127 \\ *E-mail: fwidyantama@gmail.com
}

Diterima: 09-04-2021; Direvisi: 25-07-2021; Dipublikasi: 25-08-2021

\begin{abstract}
Abstrak
Energi air adalah salah satu energi alternatif dengan potensi yang sangat besar di Indonesia yang dimanfaatkan sebagai pembangkit listrik yang memanfaatkan turbin air. Turbin yang dapat digunakan adalah turbin air jenis savonius dengan dua sudu. Dalam penelitian ini dibahas pengaruh pelat lengkung terhadap performa yang dihasilkan turbin air dengan menggunakan metode simulasi CFD. Dengan tiga variasi berupa pelat lengkung ukuran $1 / 2$ sisi turbin dan $1 / 4$ sisi turbin serta tanpa pelat lengkung. Hasil akhir berupa hasil performa turbin air tanpa pelat dan performa turbin air dengan dua variasi Pelat lengkung.. Data yang didapatkan pada hasil simulasi adalah data torsi aktual turbin. Hasil yang didapatkan dari penelitian ini yaitu performa yang dihasilkan turbin Savonius dengan pelat lengkung lebih baik dari performa yang dihasilkan tanpa penggunaan pelat lengkung. Pengujian dengan penggunaan Pelat lengkung ukuran $1 / 2$ sisi, pelat lengkung ukuran 1/4 sisi, dan tanpa pelat lengkung didapatkan bahwa dengan penggunaan pelat lengkung ukuran $1 / 4$ sisi menghasilkan menghasilkan koefisien daya yang tertinggi yaitu 0,049 dan daya turbin sebesar 1,56 Watt pada TSR 0,3
\end{abstract}

Kata kunci: dua sudu; pelat lengkung; savonius; simulasi

\begin{abstract}
Water energy is one of the alternative energies with enormous potential in Indonesia which is utilized as a power plant by utilizing water turbines. The turbine used is a savonius type water turbine with two blades. This research discusses the effect of protective curve-plates on the performance of the water turbine using the CFD simulation method. With three variations in the form of a plate $1 / 2$ size of the turbine side and 1/4 size of the turbine side and without a curve-plate. The final result is the performance of the water turbine without plates and the performance of the water turbine with two variations of the plate. The data obtained in the simulation results are the actual torque data of the turbine. The results obtained from this study are that the performance of the Savonius turbine with a plate is better than the performance without a plate. Tests with the use of a plate with a size of $1 / 2$, a plate with a size of $1 / 4$, and without plate, it was found that using a protective plate with a 1/4 size resulted in the highest power coefficient of 0,049 and turbine power of 1,56 Watt at TSR 0,3.
\end{abstract}

Keywords: curve plate; savonius; simulation; two blade

\section{Pendahuluan}

Diperkirakan bahwa jumlah kebutuhan energi listrik akan terus meningkat sesuai dengan data proyeksi pada Keputusan RUPTL yang dikeluarkan oleh Menteri ESDM Republik Indonesia di mana jumlah pelanggan pengguna energi listrik pada akhir tahun 2015 telah diproyeksikan sebesar 60,9 juta pelanggan dan pelanggan akan bertambah menjadi 82,57 juta pelanggan pada tahun 2025 [1]. Pengembangan sumber energi alternatif perlu untuk ditingkatkan, salah satu sumber energi alternatif yang dapat dimanfaatkan adalah energi air yang dapat dimanfaatkan dengan menggunakan turbin air. Salah satu tipe turbin air yang dapat digunakan adalah tipe rotor Savonius, salah satu tipe turbin dengan arah putaran poros vertikal maupun horizontal, yang mampu mengubah energi fluida menjadi energi mekanis dan tanpa memerlukan ketinggian seperti pada tipe turbin air yang lain. Cara kerja turbin Savonius yaitu bagian cekung atau sudu akan menerima energi berupa energi kinetik yang dihasilkan oleh fluida yang dapat berupa air atau udara. Selanjutnya energi yang akan diterima akan diubah menjadi energi gerak yang akan menggerakkan turbin dengan arah gerakan berputar [2]. Performa pada turbin air Savonius dua sudu tersebut ditingkatkan dengan menggunakan deflecting plate atau deflektor untuk mengarahkan aliran 
Fakhrul Widyantama dkk /Jurnal Rekayasa Mesin p-ISSN: 1411-6863, e-ISSN: 2540-7678 Vol.16|No.2|234-240|Agustus|2021

air agar arah aliran hanya menuju ke arah sisi terbuka dari turbin air Savonius. Pada penelitian yang telah dilakukan sebelumnya didapatkan hasil bahwa bentuk dari deflecting plate dapat memepengaruhi performa dari turbin air savonius dua sudu [3,4]. Pada penelitian ini dicoba untuk memodifikasi bentuk deflecting plate dengan membuat kontruksi menjadi lebih ringkas menjadi pelat lengkung lalu melakukan analisa performa penggunaan pelat lengkung terhadap turbin air savonius dua sudu sebelum dan sesudah menggunakan pelat lengkung, serta mengetahui pengaruhnya terhadap visualisasi distribusi tekanan dan kecepatan aliran dengan menggunakan simulasi CFD.

\section{Material dan metodologi}

\subsection{Turbin Savonius}

Pembangkit tenaga air ini dengan merubah energi air yang mengalir dari bendungan menjadi energi mekanik dengan menggunakan turbin air dan kemudian diubah lagi menjadi energi listrik dengan menggunakan generator [5]. Kemudian energi listrik tersebut dialirkan melalui rangkaian yang telah dibuat, hingga akhirnya energi listrik tersebut sampai pada pelanggan [6]. Turbin Savonius dapat memanfaatkan kecepatan aliran yang rendah dan potensi ketinggian yang rendah pada aliran sungai tersebut. Turbin Turbin air dengan jumlah sudu dua buah karena dapat menghasilkan koefisien daya yang baik [7]. Pada turbin air Savonius dua sudu dengan tipe Single-stage tanpa penggunaan shaft di antara pelat penutup (end-plates) [8] seperti yang ditunjukkan pada Gambar 1 untuk mendapatkan konfigurasi rotor Savonius agar koefisien daya yang didapatkan maksimal maka beberapa parameter geometri yang optimum dibutuhkan parameter - parameter geometri untuk mendesain sudu turbin air savonius di antaranya: Aspect Ratio $(H / D)=0,7$; Blade shape factor $(p / q)=0,2$ dengan Overlap ratio $=0$ dan diameter end-plate $=1,1 \mathrm{D}$. Penelitian dilakukan dengan menggunakan parameter desain turbin pada Tabel 1 seperti dibawah.

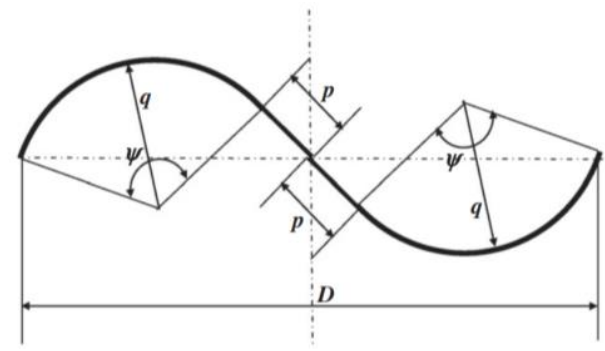

Gambar 1. Tampak Atas Parameter Geometri Turbin Savonius

Tabel 1. Parameter Desain Turbin Savonius Dua Sudu

\begin{tabular}{clll}
\hline No. & \multicolumn{1}{c}{ Parameter } & Keterangan \\
\hline 1. & Aspect Ratio $(H / D)$ & 0,7 & \\
2. & Diameter End-plate & $330 \mathrm{~mm}$ & \\
3. & Tebal End-plate & $10 \mathrm{~mm}$ & \\
4. & Diameter Turbin & $300 \mathrm{~mm}$ & \\
5. & Tinggi Turbin & $210 \mathrm{~mm}$ & \\
6. & Tebal Sudu Turbin & $2 \mathrm{~mm}$ & \\
\hline
\end{tabular}

\subsection{Deflector Plate}

Penggunaan Deflector Plate dapat meningkatkan performa turbin air Savonius dengan nilai koefisien daya tertinggi sebesar 0,21 pada TSR 0,82 peningkatan yang didapatkan tersebut naik dari performa awal dengan hasil tanpa penggunaan deflector plate dengan nilai koefisien daya sebesar 0,14 di TSR 0,7 [9]. Beberapa jenis kontruksi Deflector Plate bertujuan untuk mengarahkan aliran fluida ke arah tertentu atau mempersempit luas ruang keluaran fluida yang melewatinya, Kontruksi pengarah aliran dengan fungsi seperti ini juga dapat digunakan dengan tujuan meningkatkan efisiensi turbin [4]. 
Fakhrul Widyantama dkk /Jurnal Rekayasa Mesin

p-ISSN: 1411-6863, e-ISSN: 2540-7678

Vol.16|No.2|234-240|Agustus|2021

Ketebalan pelat lengkung yang digunakan sebesar $2 \mathrm{~mm}$, tinggi $230 \mathrm{~mm}$ dan terdapat 2 variasi ukuran pelat lengkung masing-masing akan menutupi Setengah sisi ( $1 / 2$ sisi) dan Seperempat sisi $(1 / 4$ sisi) dari turbin air pada sisi sudu tertutup, jarak antara pelat lengkung dengan turbin sebesar $10 \mathrm{~mm}$ [10] seperti pada Gambar 2.
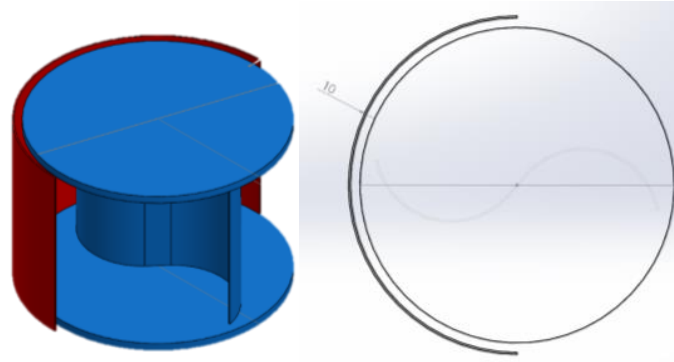

a. Pelat Setengah Sisi
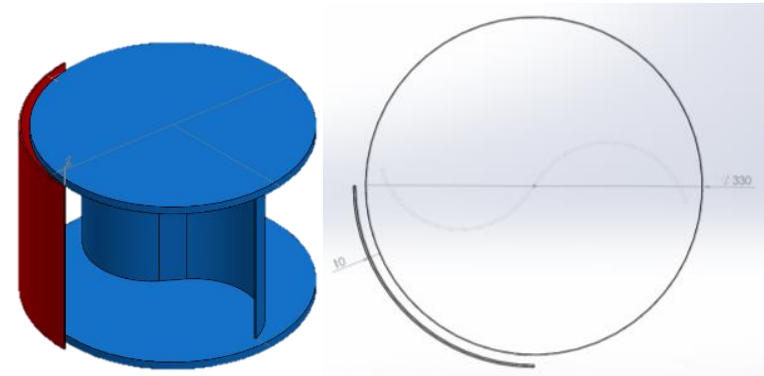

b. Pelat Seperempat Sisi

Gambar 2. Penggunaan Pelat Lengkung

\subsection{Performa Turbin}

Performa yang dapat dihitung dari turbin di antaranya Tip Speed Ratio (TSR), Koefisien Torsi $\left(\mathrm{C}_{\mathrm{T}}\right)$ dan Koefisien Daya $\left(\mathrm{C}_{\mathrm{P}}\right)$. Tip Speed Ratio (TSR) adalah rasio kecepatan ujung rotor terhadap kecepatan aliran air [11]. Diketahui bahwa nilai koefisien daya terbaik pada turbin tipe savonius terdapat pada nilai TSR antara 0,1 sampai 1 [12]. Nilai TSR suatu turbin dapat diketahui dengan menggunakan persamaan (1) sebagai berikut

$$
\begin{aligned}
& \text { TSR }=\lambda=\frac{\omega D}{2 V} \\
& \omega=\frac{2 \pi n}{60}
\end{aligned}
$$

Di mana $\boldsymbol{\omega}$ merupakan kecepatan sudut $(\mathrm{rad} / \mathrm{s}), D$ merupakan diameter turbin $(\mathrm{m}), \mathrm{V}$ adalah kecepatan aliran air $(\mathrm{m} / \mathrm{s})$ dan $\mathrm{n}$ adalah jumlah putaran dalam satuan rpm [8].

Koefisien Torsi $\left(C_{T}\right)$ adalah rasio perbandingan antara torsi aktual yang dihasilkan oleh rotor dan torsi yang diterima rotor turbin. Persamaan (3) merupakan koefisien torsi yang dapat dituliskan sebagai berikut.

$$
C_{T}=\frac{4 T}{\rho A_{s} D V^{2}}=\frac{4 T}{\rho V^{2} D^{2} H}
$$

Di mana $T$ adalah torsi aktual turbin, $D$ adalah diameter turbin, $\rho$ merupakan massa jenis air dan $H$ adalah tinggi turbin [13].

Lalu koefisien daya $\left(C_{P}\right)$ merupakan rasio perbandingan antara daya maksimum yang pada turbin $\left(P_{t}\right)$ dengan daya total $\left(P_{a}\right)$ yang dihasilkan oleh fluida yang melewati turbin. Daya pada turbin dapat diketahui dengan menggunakan persamaan (4) berikut [13].

$$
P_{t}=\omega \cdot T
$$

Dan persamaan koefisien daya $\left(C_{P}\right)$ [9] dapat dituliskan pada persamaan (5) sebagai berikut.

$$
C_{P}=T S R \times C_{T}
$$

\subsection{Metode Computational Fluid Dynamics (CFD)}

Penelitian ini memakai metode Computational Fluid Dynamics (CFD) dengan menggunakan software ANSYS CFX 2020 R2. Computational Fluid Dynamics (CFD) merupakan suatu teknik menganalisis sistem yang melibatkan suatu aliran fluida, perpindahan panas ataupun reaksi kimia menggunakan simulasi komputer atau metode numerik. Metode Computational Fluid Dynamics (CFD) dibuat dengan tujuan untuk membuat prediksi secara akurat melalui simulasi, 
Fakhrul Widyantama dkk /Jurnal Rekayasa Mesin

p-ISSN: 1411-6863, e-ISSN: 2540-7678

Vol.16|No.2|234-240|Agustus|2021

membantu mengintepretasikan dan memahami hasil teori dan eksperimen. Pada Proses simulasi CFD diperlukan tiga langkah dasar yaitu berupa pre-processing, processing, dan post-processing [14]. Dilakukan pembuatan static domain yang dibagi menjadi tiga bagian yaitu pada bagian sisi inlet, sisi outlet dan sisi tengah sedangkan rotating domain hanya satu bagian yaitu pada turbin. Untuk sisi tengah static domain dan rotating domain menggunakan meshing jenis tetrahedron sedangkan static domain seperti pada Gambar 3 dan memasukkan kondisi batas dengan yang tertera pada Tabel 2.

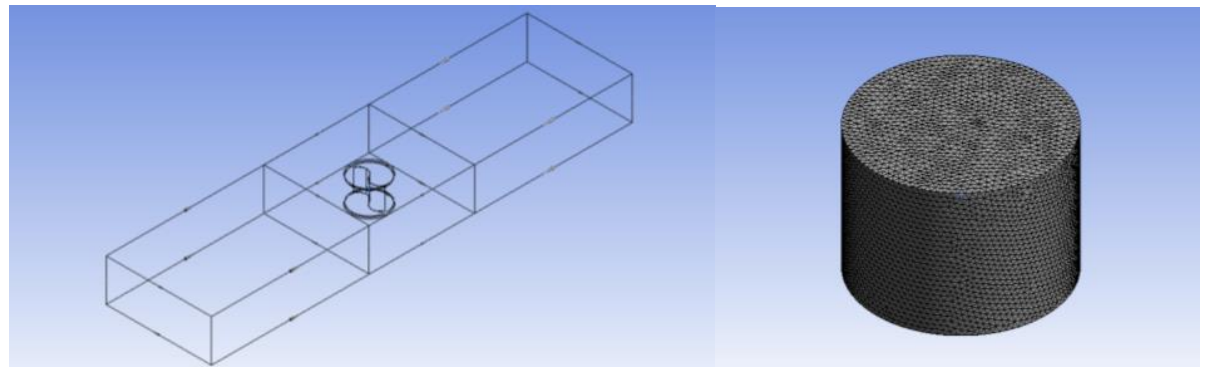

Gambar 3. Domain dan Meshing

Tabel 2. Kondisi Batas

\begin{tabular}{cll}
\hline No. & \multicolumn{1}{c}{ Kondisi Batas } & \multicolumn{1}{c}{ Pengaturan Kondisi Batas } \\
\hline 1. & Analysis Type & Steady State \\
2. & Permodelan Turbulensi & Shear Stress Transport (SST) \\
3. & Inlet & Normal Speed $1 \mathrm{~m} / \mathrm{s}$ \\
4. & Outlet & Static Pressure, Relative Pressure: 0 \\
5. & Sisi Static Domain & atm \\
6. & Reference Pressure & No Slip Wall \\
7. & Relative Pressure & 1 atm \\
8. & Rotating Domain Input & Oatm \\
9. & Frame Change Option & Revolutions per minute $(r p m)$ \\
10. & Pitch Change Option & Frozen Rotor \\
\end{tabular}

\section{Hasil dan pembahasan}

\subsection{Performa Turbin Air}

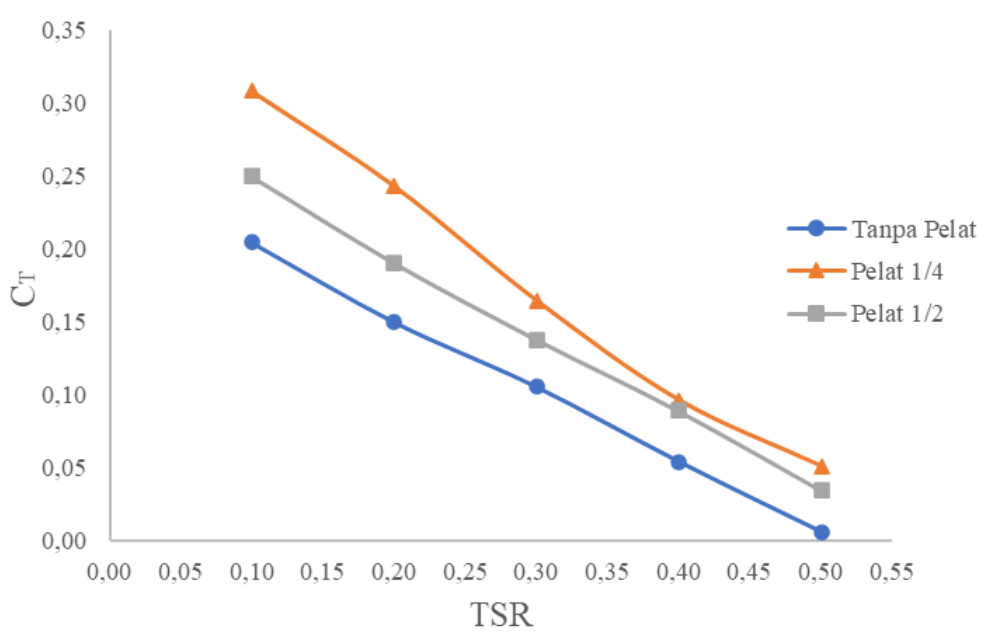

Gambar 4. Grafik Perbandingan koefisien torsi $\left(\mathrm{C}_{\mathrm{T}}\right)$ 
Fakhrul Widyantama dkk /Jurnal Rekayasa Mesin p-ISSN: 1411-6863, e-ISSN: 2540-7678 Vol.16|No.2|234-240|Agustus|2021

Hasil Simulasi yang didapatkan berupa torsi aktual turbin, kemudian dilakukan perhitungan untuk mendapatkan nilai koefisien torsi $\left(\mathrm{C}_{\mathrm{T}}\right)$ dari turbin air lalu dibuatkan grafik perbandingan untuk setiap variasi dapat diketahui pada Gambar 4 bahwa nilai perolehan koefisien torsi $\left(\mathrm{C}_{\mathrm{T}}\right)$ pada turbin air dengan menggunaan pelat lengkung lebih tinggi dari pada nilai dengan turbin tanpa penggunaan pelat lengkung, nilai tersebut didapatkan untuk setiap variasi TSR yang dipakai pada percobaan ini. Nilai tertinggi didapatkan variasi turbin dengan menggunakan pelat lengkung dengan ukuran 1/4 sisi turbin, lalu diikuti oleh turbin dengan menggunakan pelat lengkung dengan ukuran $1 / 2$ sisi turbin dengan nilai lebih rendah dari turbin dengan pelat lengkung $1 / 4$ sisi. Seluruh Nilai koefisien torsi tertinggi didapatkan pada TSR 0,1 di mana untuk variasi turbin tanpa pelat lengkung didapatkan nilai maksimum sebesar 0,2043, lalu untuk variasi turbin dengan pelat lengkung ukuran $1 / 2$ sisi sebesar 0,2494 dan nilai terbesar terdapat pada variasi turbin dengan pelat lengkung ukuran $1 / 4$ sisi dengan nilai sebesar 0,3080 .

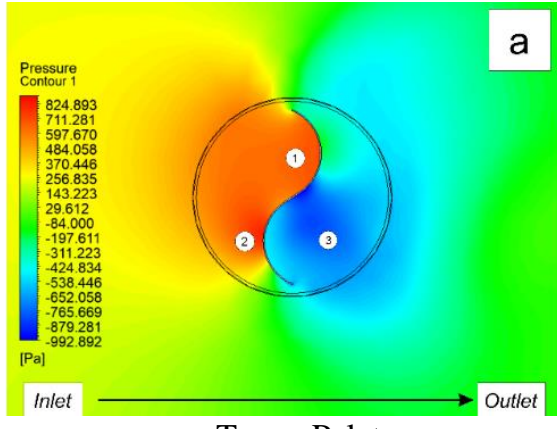

a. Tanpa Pelat

a

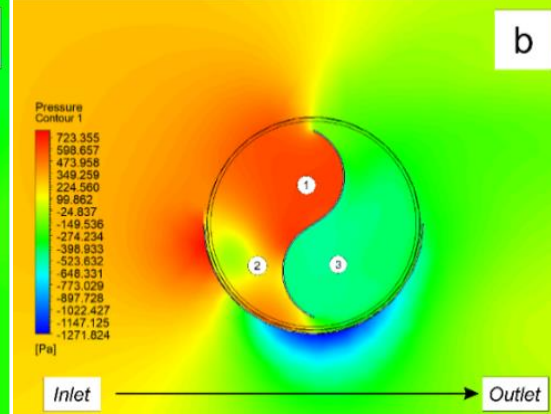

b. Pelat Setengah Sisi
C

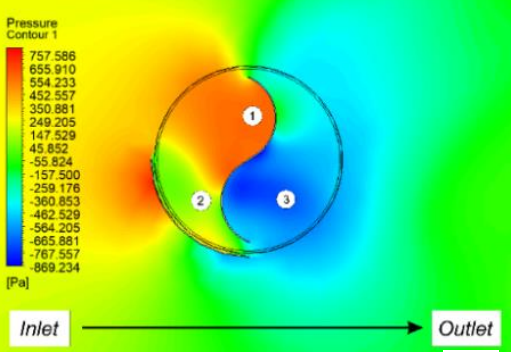

c. Pelat Seperempat Sisi

Gambar 5. Kontur Tekanan Turbin Air

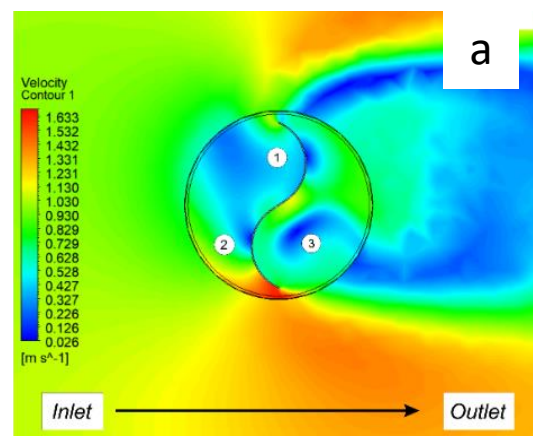

a. Tanpa Pelat

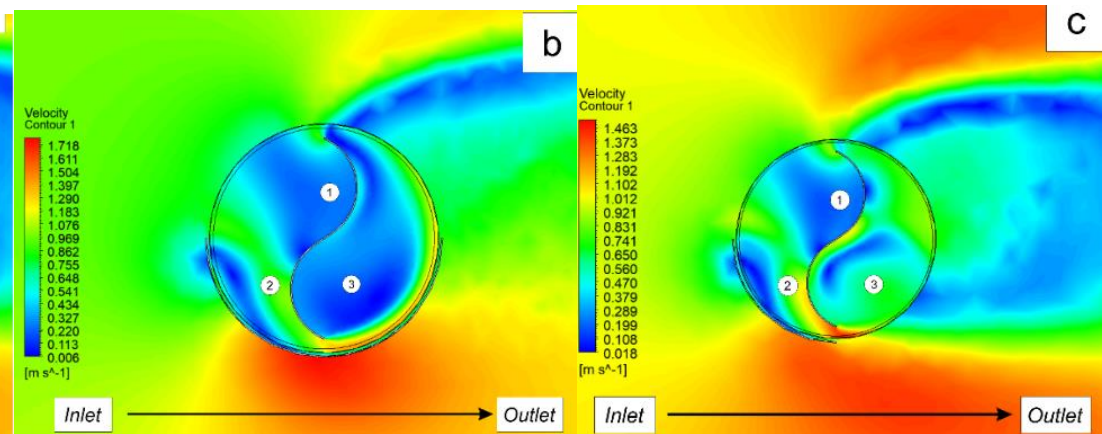

b. Pelat Setengah Sisi

c. Pelat Seperempat Sisi

Gambar 6. Kontur Kecepatan Turbin Air

Pada Gambar 5 merupakan hasil kontur dari tekanan dan Gambar 6 adalah hasil kontur kecepatan yang bekerja pada turbin air pada variasi penggunaan pelat lengkung. Dengan menggunakan Gambar 5, dapat dilakukan perbandingan kontur tekanan untuk setiap variasi ukuran pelat lengkung. Pada gambar kontur tekanan dan kecepatan tersebut dapat dilihat aliran air mengarah dari inlet menuju outlet. Pada masing-masing daerah turbin pada Gambar 5 dan Gambar 6 terdapat tiga variasi yaitu : variasi (a) yaitu tanpa pelat, kemudian variasi (b) yaitu turbin dengan pelat setengah sisi dan variasi (c) turbin dengan pelat seperempat sisi. Pada Gambar 5 dan 6 untuk setiap variasi juga telah dipetakan tiga daerah, di mana pada daerah nomor 1 merupakan daerah sudu terbuka turbin lalu daerah nomor 2 merupakan daerah sudu tertutup dan daerah nomor 3 merupakan daerah belakang turbin. Daerah tersebut dipetakan untuk mengetahui perbedaan nilai kontur untuk setiap variasi penggunaan pelat lengkung. Diketahui bahwa persebaran tekanan atau distribusi tekanan ini juga dapat mengambarkan gaya drag yang diterima oleh sudu turbin terutama pada sudu terbuka untuk memutar turbin air savonius [15], Sehingga 
Fakhrul Widyantama dkk /Jurnal Rekayasa Mesin p-ISSN: 1411-6863, e-ISSN: 2540-7678 Vol.16|No.2|234-240|Agustus|2021

hasil perolehan nilai tekanan tersebut dapat dikaitkan dengan hasil perolehan nilai torsi dan hasil perhitungan koefisien torsi $\left(\mathrm{C}_{\mathrm{T}}\right)$.

Pada Gambar 5(a) kontur tekanan yang terjadi pada variasi turbin tanpa pelat mengakibatkan kinerja atau performa turbin air savonius kurang baik, karena turbin air savonius bekerja dengan menerima aliran fluida dan menyentuh sudu terbuka (daerah nomor 1) kemudian memberikan gaya untuk memutar turbin, di mana pada percobaan ini adalah arah putaran searah jarum jam, sedangkan apabila ada aliran yang arahnya sama mengenai sudu tertutup (daerah nomor 2) maka akan memberikan gaya yang sebaliknya atau melawan arah jarum jam pada percobaan ini. Sehingga akumulasi gaya untuk memutar turbin akan lebih besar jika pada gaya yang diterima pada sisi tertutup (daerah nomor 2) tersebut nilainya lebih kecil. Kontur tekanan pada Gambar 5 daerah nomor 2 untuk setiap variasi a, b dan c terdapat perbedaan kontur nilai tekanan yang terjadi pada sudu tertutup turbin, pada variasi tanpa pelat didapatkan nilai yang cukup besar yaitu sekitar 824 Pa lalu pada penggunaan pelat lengkung sebesar $473 \mathrm{~Pa}$ dan didapatkan hasil terbaik pada penggunaan pelat lengkung ukuran 1/4 Sisi dengan nilai sebesar $147 \mathrm{~Pa}$. Hasil perolehan nilai tekanan tersebut dapat dikaitkan dengan hasil perolehan nilai torsi pada turbin dan hasil perhitungan koefisien torsi $\left(\mathrm{C}_{\mathrm{T}}\right)$ yang telah dilakukan karena dengan mengurangi nilai tekanan pada sudu tertutup dapat mengurangi nilai torsi negatif, di mana didapatkan hasil terendah terjadi pada variasi turbin tanpa pelat pelindung lalu diikuti oleh variasi turbin dengan pelat lengkung $1 / 2$ sisi dan untuk hasil terbaik dihasilkan oleh variasi turbin dengan pelat lengkung $1 / 4$ sisi.

Dengan membuat grafik antara hasil perhitungan koefisien daya $\left(\mathrm{C}_{\mathrm{P}}\right)$ dengan $\mathrm{TSR}$, lalu dilakukan perbandingan untuk setiap variasi turbin tanpa penggunaan pelat lengkung, penggunaan pelat lengkung $1 / 2$ sisi serta pelat lengkung $1 / 4$ sisi. Grafik perbandingan koefisien daya $\left(\mathrm{C}_{\mathrm{P}}\right)$ ditunjukkan pada Gambar 7 di bawah ini.

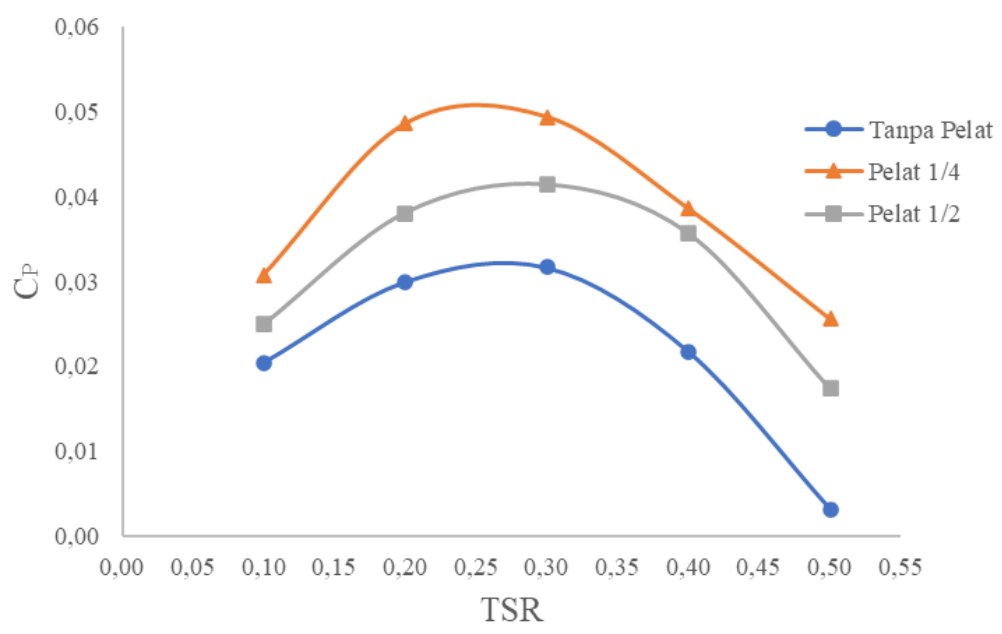

Gambar 7. Grafik Perbandingan Koefisien Daya $\left(\mathrm{C}_{\mathrm{P}}\right)$

Pada Gambar 7 dapat diketahui bahwa grafik untuk setiap variasi penggunaan pelat lengkung mengalami pengingkatan pada TSR 0,2 lalu mencapai nilai tertinggi pada TSR 0,3 kemudian nilai turun pada TSR 0,4 hingga TSR 0,5 hal tersebut dikarenakan nilai Koefisien Torsi $\left(\mathrm{C}_{\mathrm{T}}\right)$ yang semakin kecil seiring dengan penambahan nilai TSR. Sedangkan untuk perbandingan perolehan nilai koefisien daya yang ditunjukkan pada grafik, didapatkan bahwa perolehan koefisien daya terbesar didapatkan oleh variasi turbin air dengan penggunaan pelat lengkung $1 / 4$ sisi dengan nilai maksimal sebesar 0,0494 pada TSR 0,3 . Lalu diikuti oleh turbin air dengan variasi penggunaan pelat lengkung $1 / 2$ dengan nilai koefisien daya sebesar 0,0414 pada TSR 0,3 dan variasi turbin tanpa pelat lengkung dengan nilai 0,0317 pada TSR 0,3 sebagai variasi paling rendah untuk perolehan nilai koefisien daya pada percobaan ini. 
Fakhrul Widyantama dkk /Jurnal Rekayasa Mesin p-ISSN: 1411-6863, e-ISSN: 2540-7678 Vol.16|No.2|234-240|Agustus|2021

\section{Kesimpulan}

Penggunaan pelat lengkung aliran dapat meningkatkan performa turbin air sumbu vertikal tipe savonius 2 sudu karena mengurangi nilai torsi negatif pada sudu tertutup turbin air Savonius. Pada variasi tanpa menggunakan pelat lengkung aliran menghasilkan koefisien daya sebesar 0,031 sedangkan pada penggunaan pelat lengkung ukuran 1/2 sisi koefisien daya sebesar 0,0414 dan pada penggunaan pelat lengkung ukuran $1 / 4$ sisi menghasilkan koefisien daya yang tertinggi yaitu 0,049 dan daya turbin sebesar 1,56 Watt pada TSR 0,3.

\section{Daftar Pustaka}

[1] Kementrian Energi dan Sumber Daya Mineral, Pengesahan RUPTL PLN 2016-2025. Jakarta; 2016.

[2] Muliawan A, Yani A., Analisis Daya dan Efisiensi Turbin Air Kinetis akibat Perubahan Putaran Runner. Journal of Sainstek. 2016; 8(1): p. 1-9.

[3] Putra, Y. Pengaruh Jumlah Sudu terhadap Unjuk Kerja Kincir Air Poros Vertikal Tipe Savonius. Yogyakarta: Universitas Sanata Dharma; 2018. P.53.

[4] Abadi, RP., Turbin Air Poros Vertikal Tipe Savonius Dua Sudu Terbuka dengan menggunakan Deflektor. Yogyakarta: Universitas Sanata Dharma; 2018. P.49.

[5] Kemdikbud, Turbin Air dan Kelengkapan Mekanik. Jakarta: Direktorat Jenderal Guru dan Tenaga Kependidikan; 2015. p 89.

[6] Zain, M.A., Simulasi Perancangan Pembangkit Listrik Tenaga Pico Hydro menggunakan Mini Water Pump. Vol. 87. Medan: Universitas Muhammadiyah Sumatera Utara; 2019. P.8.

[7] Fendiyatma, A.P., Pengaruh dari Jumlah Sudu untuk Kinerja Kincir Air Savonius Poros Vertikal dengan menggunakan Deflektor. Yogyakarta: Universitas Sanata Dharma; 2018. P.49.

[8] Kamoji, M.A., Kedare, S.B., Prabhu, S. V., Experimental Investigations on Single Stage Modified Savonius Rotor. Applied Energy. 2009 Juli; 86(7-8): p. 1064-1073 .

[9] Golecha K., Eldho T.I., Prabhu S.V., Influence of the Deflector Plate on the Performance of Modified Savonius Water Turbine. Applied Energy. 2011 September; 88(9): p. 3207-3217.

[10] Rendi, Herlina, F., Penambahan Lingkaran Pelindung pada Turbin Air Rotor Savonius. Info-Teknik. 2019 Desember; 20(2): p. 237-254.

[11] Purnama, A.C., Hantoro, R., Nugroho, G., Rancang Bangun Turbin Air Sungai Soros Vertikal Tipe Savonius dengan menggunakan Pemandu Arah Aliran. JURNAL TEKNIK POMITS. 2013; 2(2): p. 278-282.

[12] Cengel Y, Cimbala., Fluid Mechanics: Fundamentals and Applications, 3rd ed. McGraw-Hill Companies, Inc., New York, NY. Boston: McGraw-HillHigher Education; 2010. p 854.

[13] Wenehenubun, F., Saputra, A., Sutanto, H., An Experimental Study on the Performance of Savonius Wind Turbines Related with the Number of Blades. Energy Procedia; 2015 April. p. 297-304.

[14] Risaldi, M., Simulasi Pengaruh Penggunaan Winglet pada Turbin Angin Sumbu Horizontal 3 Blade Propeller dengan Metode CFD. Balikpapan: Institut Teknologi Kalimantan; 2020. P.20-22.

[15] Ubaidillah, M., Studi Eksperimen Pengaruh Plat Datar sebagai Penggangu Aliran di Depan Returning Blade terhadap Performa Turbin Angin Savonius. Surabaya: Institut Teknologi Sepuluh Nopember; 2017. P.80. 